area. On the other hand, the exclusive reflex activity of the lower extremities to peripheral stimuli in cases of paraplegia is a common observation; transcending the normal in extent and degree. Cases are presented by the writer illustrating some of the peculiarities and derangements of the cutaneous reflex action in spastic cases. The concluding remarks are as follows: In affections of the pyramidal tracts, the diminution or abolition of the abdominal and cremasteric reflexes arc in contrast, it is true, with the exaggeration of the tendon reflexes. If the cutaneous reflexes are considered from a general standpoint and an attempt is made to express the essential nature of the disturbance which thcy suffer. it would not be just to say that they were-abolished in contrast to, nor correct that they are exaggerated as are the tendon reflexes in spastic cases. What could be said is that the law governing the cutaneous rcflexes suffers a transformation.

J. Ramsay Hunt (New York).

\title{
MISCELLANY
}

A Case of Acute Disseminated Encephalomyelitis. Joseph L. Miller (Journal of the American Medical Association, Oct. 24, I903).

Acute disscminated encephalomyelitis manifests itself in one of two clinical types, acute ataxia or acute paraplegia.

The author rcports a case of a man aged 47 , alcoholic and syphilitic, who had sustained a severe traumatism to the leg. During an attack of pneumonia he suddenly developed temporary aphasia. Later he suddenly developed a staggering gait, slow, monotonous speech; he suffered remissions in his disturbance of gait; a slight tremor of the hands when at rest or in motion; horizontal nystagmus, and no optic atrophy.

This is a clinical picture of multiple sclerosis, but differs from it by its acute onset. Pathologists agrec that the anatomical findings may be identical with multiple sclerosis. Many writers consider the cases of this type multiple sclerosis with acute onset.

W. B. NoYes.

\section{An Early Sign of General Paralysis.}

E. Toulouse and $\mathrm{Cl}$. Vurpas, at the $\mathrm{I} 3^{\text {th }}$ congress of alienists, held at Brussels, have called the attention to a ncw sign of paresis, by modifying the pupillary rcflex by applying eserine and atropine to the eye. In the latent period of the disease the reaction to these drugs does not appear at all; in the time of reaction or later period of paresis a few drops of either drug will produce a maximum effect in a short time.

W. B. NOYES.

Inhibition in the Mevusd. L. Sanzo (Arch. Ital. de Biologie. Oct. Io, 1903).

As a physiological process, inhibition is manifested not only in the highly complex organisms, but also in those at the lower end of the scale of animal life. L. Sanzo, stimulated by the observations of Romanes and Krukenberg, namely, that the rhythmic contractions of the jelly-fish are analogous to those of the frog's heart, decided to investigate the problem whether inhibition plays any rôle in the vital manifestations of this organism. He finds that the contractions are truly rlyythmical. In treating the animal to the action of pilocarpine, nicotine or muscarine, which stops the action of the heart in the higher animals, the author discovers that the contractions after an increase in energy and frequency, soon diminish and then stop in diastole. The author then inquires whether this is due to an exaggeration of the normal process of inhibition or is to be attributed to the toxicity of the substance employed. He finds that the excitability of the muscular fibers and the conductivity of the nerves are still preserved, that the action is evidently limited to the ganglia. To solve the question whether the drug stimulates normal process of inhibition in the latter or paralyzes 
them, the author resorted to the following: In injecting atropine into a medusa whose contractions have already ceased as the result of the action of pilocarpine, the author finds that the movements begin again. The interpretation of these facts is that pilocarpine, nicotine and muscarine, in small doses, excite and exaggerate a normal process of inhibition exercised by the ganglia, and atropine, in paralyzing the ganglia or the peripheral extremities of the inhibitory nerves, counteracts this process. In whatever manner it is brought about, the above show that there is undoubtedly an inhibitory process in the normal rhythmical movements of the medusa, which is all the more interesting since this animal is one of the first in the zoological scale to show a nervous apparatus, the process of inhibition thus appearing synchronously with the phylogenetic origin of the muscular and nervous tissues.

JeLLIFFE.

Tile Differential. Diagnosis Between Friedreich's Disense and In$\therefore l$ lar Sclerosis. F. Savery Pearce (N, X. Med. Journ., Oct. 24, Ig03).

Friedreich's disease, a non-system disease, consisting of gliosis principally involving the posterior columns, presents incoordination in all four extremities, a jerky or reeling gait, loss of knee jerks, nystagmus, disturbance of articulation (stumbling or blurred speech), and a progressive tendency to helplessness. It is distinguished from Narie's form by occuring before, instead of after, puberty; the choreiform movements of the head, arm and trunk are very pronounced in Marie's form. Optic atrophy is exceptional in Friedreich's, common in Marie's form. 'Tendon reflexes are diminished in the former, increased in the latter, with clonus; club foot and scoliosis are common in Friedreich's, exceptional in Marie's form. Insular sclerosis is a disease caused by sclerotic plaques scattered through the central nervous system, and as a rule occurs between the years twenty and thirty, though sometimes congenital and hereditary.

The gait may be spastic, cerebello-spastic, or cerchellar, in the latter there being rigidity with diminished or normal reflexes; but nystagmus, staccato speech, and intention tremor are always present. Sometimes the Marie type of Friedreich's disease may be confused with insular sclerosis, but the former may show an alcoholic history, has few remissions, no intention tremor of the tongue or hand. In instular sclcrosis the scanning speech and distinct intention tremor of the hand is present. The disease is an evolutionary defect.

IV. B. NoYES.

A Serinate Center for Writing. llermon C. Gordinier (Am. Journ. Med. Sciences, Scpl., 1903).

Autopsy in a case operated on for supposed cereloral ncoplasm showed a glioma occupying the foot of the second left frontal convolution, being distinctively separated from the arm area by the precentral sulcus. The growth was elevated about $0.5 \mathrm{c} . \mathrm{m}$. above the surrounding cortex, was slightly irregular in outline, of a distinctly firm consistency and oval in shape. Its longest cortical diameter was $2 \mathrm{~cm}$. The pia was intimately adherent to it. The tumor was seen to cxtend downward and inward in the centrum semiovale as far as the roof of the anteriot cornu of the lateral ventricle, and forward to near the apex of the frontal lobe, involving almost exclusively the white matter of the second frontal gyrus. The rest of the lorain was normal.

The symptoms that had been caused by this were failure of strength and occasional attacks of vertigo during six months preceding her death; headaches of increasing severity, gradual failure of sight, due to optic neuritis; paresis of the right external rectus muscle. No aphasia, either motor or sensory, but a total inability to write was present, although understanding perfectly written language. There was no paralysis of the 